\title{
FORMAÇÃO CONTINUADA DE PROFESSORES: PARCERIA ENTRE PROFMAT, EDUCAÇÃO INFANTIL E ANOS INICIAIS DO ENSINO FUNDAMENTAL
}

\section{CONTINUOUS TEACHER EDUCATION: PARTNERSHIP BETWEEN PROFMAT, CHILDHOOD EDUCATION AND EARLY YEARS OF ELEMENTARY EDUCATIO}

\author{
Ana Maria Porto Nascimento ${ }^{1}$ \\ Arthur do Amaral Rocha ${ }^{2}$ \\ Fabiana Alves dos Santos ${ }^{3}$ \\ Priscila Santos Ramos ${ }^{4}$
}

\begin{abstract}
RESUMO: Este artigo registra a releitura dos resultados de uma pesquisa de mestrado do Programa de Mestrado Profissional em Matemática em Rede Nacional (Profmat), a fim de identificar as contribuições para a formação continuada dos professores da Educação Infantil e Anos Iniciais do Ensino Fundamental que ocorreu por meio da parceria entre a pós-graduação e a Educação Básica. A pesquisa investigou como professores atuantes nesses segmentos exploram tópicos de Estatística em suas práticas pedagógicas. Adotou-se uma abordagem qualitativa e os sujeitos da pesquisa foram 13 alfabetizadoras que atuaram, no ano de 2020, no I e II Período da Educação Infantil, e nas classes do 1ํㅜ ao $5^{\circ}$ ano do Ensino Fundamental. Os instrumentos de pesquisa foram análise do eixo Estatística na BNCC; encontros com as professoras via Google Meet; seleção de situações no livro didático; elaboração e desenvolvimento de aulas. A releitura dos resultados discutidos na dissertação indica que a pesquisa, realizada no Curso de Mestrado, constituiu-se como formação pedagógica do mestrando e integrou-se à formação matemática, proporcionada pelo Profmat; a visão do mestrando sobre a atividade profissional do professor que atua na Educação Básica foi ampliada; o trabalho do mestrando como coordenador pedagógico da área de Matemática foi aperfeiçoado; a pesquisa configurou-se como atividade de formação continuada para as professoras e uniu a Universidade e a escola de Educação Básica. A ação das professoras formadoras do Profmat, ao orientar a pesquisa e refletir sobre os impactos na formação do mestrando e na formação continuada dos professores, provocou uma sensibilização e motivou a continuidade do trabalho em parceria com os professores da Educação Básica.
\end{abstract}

PALAVRAS- CHAVE: Educação Básica. Formação Continuada. Estatística.

\footnotetext{
${ }^{1}$ Universidade Federal do Oeste da Bahia. E-mail: ana.nascimento@ufob.edu.br

(D) https://orcid.org/0000-0003-2048-5554

2 Universidade Federal do Oeste da Bahia. E-mail: arthur_rocha99@hotmail.com

(iD) https://orcid.org/000-00021406-8861

3 Universidade Federal do Oeste da Bahia. E-mail: fabiana.santos@ufob.edu.br

(iD) https://orcid.org/0000-0002-5271-9231

${ }^{4}$ Universidade Federal do Oeste da Bahia. E-mail: priscilasr@ufob.edu.br

(iD) https://orcid.org/0000-0003-3394-764X
}

ABSTRACT: This article records the re-reading of the results of a Profmat master's research, in order to identify the contributions to the continuing education of teachers in Childhood and Early Years of Elementary Education in the partnership between graduate and Basic Education. The research investigated how teachers working in these segments explore Statistics topics in their pedagogical practices. A qualitative approach was adopted and 13 literacy teachers who worked, in 2020, in the I and II Period of Early Childhood Education, and in the classes from the 1st to the 5th year of Elementary School, were subject. The research instruments

- Informações completas da obra no final do artigo 
were analysis of the Statistical axis at BNCC; meetings with teachers via Google meet; selection of situations in the textbook; elaboration and development of classes. The re-reading of the results discussed in the dissertation indicates that the research in the Master's Course was constituted as a pedagogical training of the master's student and was integrated to the mathematical training provided by Profmat; the view of the master's student on the professional activity of the teacher who works in Basic Education was expanded; the master's work as a pedagogical coordinator in the area of mathematics was improved; the research was configured as a continuing education activity for teachers and united the University with the School of Basic Education, and the action of the teachers who train the Profmat, by guiding the research and reflecting on the impacts on the formation of the master's student and on continuing education of teachers provoked awareness and motivated to continue the work in partnership with teachers of Basic Education.

KEYWORDS: Basic education. Continuing Education. Statistic.

\section{Introdução}

Este texto registra a releitura dos resultados de uma pesquisa, realizada no curso de mestrado do Programa de Mestrado Profissional em Matemática em Rede Nacional (Profmat) em parceria com a Universidade Federal do Oeste da Bahia - Profmat/UFOB, sob a orientação das formadoras, pesquisadoras e coautoras deste trabalho, a fim de identificar as contribuições para a formação continuada dos professores da Educação Infantil e Anos Iniciais do Ensino Fundamental.

A referida pesquisa foi realizada por um dos autores deste artigo com o objetivo de investigar como professores que atuam na Educação Infantil e Anos Iniciais do Ensino Fundamental, na cidade de Corrente - Piauí, exploram tópicos da Unidade Temática Estatística prescritos na Base Nacional Comum Curricular (BNCC) (BRASIL, 2017), em suas práticas pedagógicas.

As seguintes questões nortearam a pesquisa: quais as orientações metodológicas para o eixo de Estatística estão contidas na BNCC para Educação Infantil e anos iniciais? $E$ de que forma os professores atuantes nesses segmentos exploram esse eixo? Foram estudados tópicos referentes à aprendizagem matemática na Educação Infantil e nos Anos Iniciais do Ensino Fundamental, principalmente sobre a alfabetização matemática, analisada a BNCC, especificamente as orientações referentes ao eixo de Estatística. Além disso, foram estudados tópicos sobre pesquisa colaborativa, pois o mestrando tinha uma parceria consolidada com o grupo de professoras e atuava como coordenador pedagógico na área de Matemática na escola em que foi realizada a pesquisa. Esses estudos constituíram o referencial teórico e metodológico da pesquisa. 
As professoras colaboradoras da pesquisa atuavam na Educação Infantil e nos Anos Iniciais do Ensino Fundamental com tempo de experiência em sala de aula entre 1 e 15 anos. Inicialmente identificou-se, junto com as professoras, o que está proposto na BNCC. Em seguida, os planos de aula foram elaborados, desenvolvidos e analisados.

Assim, apresentam-se, neste artigo, o percurso da pesquisa, os referenciais teóricos, alguns resultados e as reflexões feitas pelas professoras formadoras do Profmat, junto com o mestrando, a partir da releitura de sua dissertação, em que foram analisadas indicações para a continuidade da pesquisa em parceria com as professoras atuantes na Educação Infantil e Anos Iniciais do Ensino Fundamental.

Entre as principais indicações, é possível ressaltar que a pesquisa, durante o Curso de Mestrado, constituiu-se como formação pedagógica do mestrando e integrou-se à formação matemática, proporcionada pelo curso Profmat; a visão do mestrando sobre a atividade profissional do professor que atua na Educação Infantil e nos Anos Iniciais do Ensino Fundamental foi ampliada; o trabalho do mestrando como coordenador pedagógico da área de Matemática foi aperfeiçoado; a pesquisa configurou-se como atividade de formação continuada que uniu a Universidade, via pós-graduação, com a escola de Educação Básica.

Além dos resultados apontados, destaca-se que, nesse processo, a ação das professoras formadoras do Profmat, que têm formação específica em Matemática, ao orientar a pesquisa e refletir sobre os impactos na formação do mestrando e na formação continuada dos professores, provocou uma sensibilização destas formadoras, motivandoas a continuar o trabalho em parceria com os professores da Educação Básica. Essas indicações de continuidade da pesquisa serão discutidas ao longo deste artigo.

\section{O ensino de Matemática nos primeiros segmentos da Educação Básica}

Os referenciais teóricos que embasaram a pesquisa foram constituídos a partir das perguntas: Quais são os segmentos da Educação Básica? Qual a formação do professor que ensina Matemática na Educação Básica, especificamente na Educação Infantil e Anos Iniciais do Ensino Fundamental? O que significa a alfabetização matemática? O que constitui o eixo Estatística na Educação Infantil e nos Anos Iniciais do Ensino Fundamental? Como se caracteriza a formação continuada dos professores desses segmentos? 
A Educação Básica tem caráter obrigatório e é regulamentada pela Lei de Diretrizes e Bases da Educação Nacional (LDB) (BRASIL, 1996). Ela engloba a Educação Infantil, o Ensino Fundamental e o Ensino Médio, sendo a Educação Infantil a primeira etapa da Educação Básica, caracterizando-se como fundamento do processo educacional.

A BNCC (BRASIL, 2017) propõe seis direitos de aprendizagem e desenvolvimento na etapa Educação Infantil, para que se assegurem as condições de aprendizagem. As ideias fundamentais desses direitos são: conviver, brincar, participar, explorar, expressarse e conhecer-se. Assim, a organização curricular da BNCC para a Educação Infantil está estruturada não em disciplinas ou componentes curriculares, mas em torno de cinco campos de experiências, que são: (1) O eu, o outro e o nós; (2) Corpo, gestos e movimentos; (3) Traços, sons, cores e formas; (4) Escuta, fala, pensamento e imaginação; (5) Espaços, tempos, quantidades, relações e transformações. Apesar de não haver uma separação de componentes curriculares, nós conseguimos perceber a presença da Matemática, especialmente no campo 5: Espaços, tempos, quantidades, relações e transformações.

O Ensino Fundamental inicia-se aos 6 anos e tem duração de 9 anos. O principal objetivo dessa etapa de ensino é o desenvolvimento da capacidade de aprender, tendo como meios básicos o pleno domínio da leitura, da escrita e do cálculo. Os Anos Iniciais do Ensino Fundamental é o período constituído do $1^{\circ}$ ao $5^{\circ}$ ano. Em relação à Matemática, a BNCC (BRASIL, 2017) prevê que:

[...] essa área, por meio da articulação de seus diversos campos - Aritmética, Álgebra, Geometria, Estatística e Probabilidade -, precisa garantir que os alunos relacionem observações empíricas do mundo real a representações (tabelas, figuras e esquemas) e associem essas representações a uma atividade matemática (conceitos e propriedades), fazendo induções e conjecturas. Assim, espera-se que eles desenvolvam a capacidade de identificar oportunidades de utilização da matemática para resolver problemas, aplicando conceitos, procedimentos $\mathrm{e}$ resultados para obter soluções e interpretá-las segundo os contextos das situações. A dedução de algumas propriedades e a verificação de conjecturas, a partir de outras, podem ser estimuladas, sobretudo ao final do Ensino Fundamental (BRASIL, 2017, p. 265).

Quanto à alfabetização matemática, Nascimento (2016) apresenta que ela é um complexo processo de aprendizagem dos conceitos iniciais de Matemática, relacionados a números, operações, grandezas, medidas, formas, localização, orientação, deslocamento, estatística, probabilidade e estimativa. Para essa pesquisadora, trata-se de um processo 
em que, no envolvimento com situações-problema, a criança constrói e mobiliza tais conceitos e suas representações.

Nascimento (2016) ressalta que esse processo se inicia fora do contexto escolar, continua, é aperfeiçoado e ampliado quando a criança ingressa na escola, seja nas experiências realizadas na Educação Infantil, seja nos primeiros anos escolares do Ensino Fundamental. Nesse processo, estão implicados o aprender a linguagem matemática, conhecer os objetos matemáticos, propor, identificar e resolver situações-problema, desenvolver registros e argumentação oral lógica para comunicar as estratégias de solução e mobilizar os conceitos matemáticos em diferentes situações.

Quanto aos professores que atuam nesses segmentos, Curi (2004, p.179) diz que "nos cursos de formação de professores polivalentes a crítica que pode ser feita é a da ausência de conhecimentos específicos relativos às diferentes áreas de conhecimento, com as quais o futuro professor irá trabalhar". Isso reforça as inquietações sobre a formação da alfabetizadora, que é uma professora polivalente, isto é, trabalha com as áreas de conhecimento que constituem a proposta curricular da Educação Infantil e dos Anos Iniciais do Ensino Fundamental. E, de acordo com Curi (2006), persiste a necessidade de repensar os cursos que formam o professor que irá ensinar Matemática nos primeiros segmentos da Educação Básica. Essa pesquisadora da área de Educação Matemática alerta que devem ser consideradas nos cursos de formação de professores polivalentes as "especificidades próprias do ensino/aprendizagem de Matemática pelas crianças e as características dos professores" (CURI, 2006, p.1)

De modo geral, o profissional que atua na Educação Infantil é licenciado em Pedagogia. Pesquisas, como as de Gatti (2010), mostraram que uma formação voltada para o ensino de Matemática, que promova um sólido conhecimento dos objetos de ensino e um conhecimento pedagógico do conteúdo matemático, ainda não ocorre de modo satisfatório nesse curso. A releitura dos resultados da pesquisa do mestrando indicaram as necessidades formativas das professoras da Educação Infantil e Anos Iniciais e apontaram possibilidades de planejar ações que contribuam para o aperfeiçoamento do trabalho dessas professoras polivalentes. Isso porque se entende que a formação das alfabetizadoras precisa estar voltada não só para metodologias, mas também para conteúdos básicos de Matemática, como os que constituem o eixo de Estatística. 
Um estudo que norteou a releitura das informações obtidas na pesquisa do mestrando foi sobre a necessária formação continuada do professor. Nascimento (2016, p.148) afirma que essa formação "se constitui numa reflexão/problematização permanente, em busca de solucionar problemas que afloram a todo o momento, em sala de aula, na complexidade de ensinar, principalmente ensinar matemática". E obter os conhecimentos profissionais para o ensino, em qualquer área, implica em estudar os conteúdos, planejar e avaliar as aulas. Em Santos (2010) observa-se que:

[...] a formação continuada é considerada como estratégia de desenvolvimento profissional, na medida em que propicia situações de aprendizagem que afetam o processo do aprender a ensinar e o crescimento intelectual dos professores. Inserida nesse quadro a formação continuada denota sua importância como instrumento que concorre para o desenvolvimento pessoal e profissional, bem como favorece o processo de elaboração da prática pedagógica (SANTOS, 2010, p. 67).

Assim, a pesquisa realizada durante 0 mestrado, em parceria com as professoras, insere-se na caracterização de uma proposta de formação continuada, pois oportunizou situações de aprendizagem para as professoras atuantes, durante um período atípico, como o período de distanciamento social, em que muitos outros conhecimentos profissionais foram exigidos.

\section{O eixo Estatística na Educação Infantil e nos Anos Iniciais do Ensino Fundamental}

Diante dessas inquietações, procedemos a uma identificação das orientações contidas na BNCC (BRASIL, 2017) para o trabalho com esse eixo:

Com relação à estatística, os primeiros passos envolvem o trabalho com a coleta $\mathrm{e}$ a organização de dados de uma pesquisa de interesse dos alunos. O planejamento de como fazer a pesquisa ajuda a compreender o papel da estatística no cotidiano dos alunos. Assim, a leitura, a interpretação e a construção de tabelas e gráficos têm papel fundamental, bem como a forma de produção de texto escrito para a comunicação de dados, pois é preciso compreender que o texto deve sintetizar ou justificar as conclusões (BRASIL, 2017, p. 275).

Dessa forma, desde o início, vê-se que o recomendado é desenvolver a habilidade de pesquisar, de levantar dados, e as habilidades de ler e interpretar gráficos, de coletar dados e de organizar uma pesquisa devem ser desenvolvidas nos alunos desde os anos iniciais do Ensino Fundamental. O documento destaca que os primeiros passos envolvem o trabalho com a coleta e a organização de dados de uma pesquisa de interesse dos alunos. A leitura, a interpretação e a construção de tabelas e gráficos têm papel fundamental, bem 
como a forma de produção de texto escrito para a comunicação de dados (BRASIL, 2017, p. 273).

A pesquisadora Gitirana (2014) ressalta a importância desse eixo para a formação científica do cidadão, pois traz uma perspectiva interdisciplinar.

Aprender a fazer pesquisa favorece, não somente a formação estatística do cidadão, como, também, a formação científica. A Estatística tem importância numa perspectiva interdisciplinar, para a formação do cidadão em outras áreas do conhecimento, pois as questões a serem investigadas são geradas nos diversos campos de conhecimento (GITIRANA, 2014, p. 8).

Inferimos que a Estatística tem que ser enfatizada desde cedo nas classes de Educação Infantil e Anos Iniciais, devido a sua importância. Essa área de conhecimento pode ser trabalhada de forma interdisciplinar.

A BNCC (BRASIL, 2017) destaca que os primeiros passos envolvem o trabalho com a coleta e a organização de dados de uma pesquisa de interesse dos alunos. A leitura, a interpretação e a construção de tabelas e gráficos têm papel fundamental, bem como a forma de produção de texto escrito para a comunicação de dados (BRASIL, 2017, p. 273). A normativa legal apresenta 8 competências específicas de Matemática no Ensino Fundamental e 5 delas estão diretamente ligadas à Estatística. A seguir, transcrevemos essas competências:

3- Compreender as relações entre conceitos e procedimentos dos diferentes campos da Matemática (Aritmética, Álgebra, Geometria, Estatística e Probabilidade) e de outras áreas do conhecimento, sentindo segurança quanto à própria capacidade de construir e aplicar conhecimentos matemáticos, desenvolvendo a autoestima e a perseverança na busca de soluções.

4- Fazer observações sistemáticas de aspectos quantitativos e qualitativos presentes nas práticas sociais e culturais, de modo a investigar, organizar, representar e comunicar informações relevantes, para interpretá-las e avaliá-las crítica e eticamente, produzindo argumentos convincentes.

6- Enfrentar situações-problema em múltiplos contextos, incluindo-se situações imaginadas, não diretamente relacionadas com 0 aspecto prático-utilitário, expressar suas respostas e sintetizar conclusões, utilizando diferentes registros e linguagens (gráficos, tabelas, esquemas, além de texto escrito na língua materna e outras linguagens para descrever algoritmos, como fluxogramas, e dados).

7- Desenvolver e/ou discutir projetos que abordem, sobretudo, questões de urgência social, com base em princípios éticos, democráticos, sustentáveis e solidários, valorizando a diversidade de opiniões de indivíduos e de grupos sociais, sem preconceitos de qualquer natureza.

8- Interagir com seus pares de forma cooperativa, trabalhando coletivamente no planejamento e desenvolvimento de pesquisas para responder a questionamentos e na busca de soluções para problemas, de modo a identificar aspectos 
consensuais ou não na discussão de uma determinada questão, respeitando o modo de pensar dos colegas e aprendendo com eles (BRASIL, 2017, p. 267).

Na competência 4, podem ser destacados "investigar, organizar, representar e comunicar informações relevantes". Na competência 6, atentamos para "expressar suas respostas e sintetizar conclusões, utilizando diferentes registros e linguagens," entre eles, fluxogramas, dados, gráficos e tabelas. E na competência 7, "Desenvolver e/ou discutir projetos", "valorizando a diversidade de opiniões de indivíduos e de grupos sociais". Desse modo, vimos a relação com a formação científica do cidadão, que foi enfatizada por Gitirana (2014), e que pode ser desenvolvida com um trabalho adequado com o eixo Estatística.

Concluímos essa parte registrando os objetos de conhecimentos e as Habilidades que a BNCC (BRASIL, 2017) traz para serem desenvolvidos no eixo de Estatística nos anos iniciais do Ensino Fundamental:

Quadro 1. Objetos de conhecimento e Habilidades - Estatística

\begin{tabular}{|c|c|c|}
\hline Ano & Objetos do Conhecimento & Habilidade \\
\hline \multirow[t]{2}{*}{$1^{\circ}$ ano } & $\begin{array}{l}\text { Leitura de tabelas e de } \\
\text { gráficos de colunas simples }\end{array}$ & $\begin{array}{l}\text { (EF01MA21) Ler dados expressos em tabelas e em gráficos de } \\
\text { colunas simples. }\end{array}$ \\
\hline & $\begin{array}{l}\text { Coleta e organização de } \\
\text { informações r Registros } \\
\text { pessoais para comunicação } \\
\text { de informações coletadas }\end{array}$ & $\begin{array}{l}\text { (EF01MA22) Realizar pesquisa, envolvendo até duas variáveis } \\
\text { categóricas de seu interesse e universo de até } 30 \text { elementos, e } \\
\text { organizar dados por meio de representações pessoais. }\end{array}$ \\
\hline $2^{\circ}$ ano & $\begin{array}{l}\text { Coleta, classificação e } \\
\text { representação de dados em } \\
\text { tabelas simples e de dupla } \\
\text { entrada e em gráficos de } \\
\text { colunas }\end{array}$ & $\begin{array}{l}\text { (EF02MA22) Comparar informações de pesquisas apresentadas } \\
\text { por meio de tabelas de dupla entrada e em gráficos de colunas } \\
\text { simples ou barras, para melhor compreender aspectos da } \\
\text { realidade próxima. (EF02MA23) Realizar pesquisa em universo } \\
\text { de até } 30 \text { elementos, escolhendo até três variáveis categóricas } \\
\text { de seu interesse, organizando os dados coletados em listas, } \\
\text { tabelas e gráficos de colunas simples. }\end{array}$ \\
\hline \multirow[t]{2}{*}{$3^{\circ}$ ano } & $\begin{array}{l}\text { Leitura, interpretação e } \\
\text { representação de dados em } \\
\text { tabelas de dupla entrada e } \\
\text { gráficos de barras }\end{array}$ & $\begin{array}{l}\text { (EF03MA26) Resolver problemas cujos dados estão } \\
\text { apresentados em tabelas de dupla entrada, gráficos de barras ou } \\
\text { de colunas. } \\
\text { (EF03MA27) Ler, interpretar e comparar dados apresentados em } \\
\text { tabelas de dupla entrada, gráficos de barras ou de colunas, } \\
\text { envolvendo resultados de pesquisas significativas, utilizando } \\
\text { termos como maior e menor frequência, apropriando-se desse } \\
\text { tipo de linguagem para compreender aspectos da realidade } \\
\text { sociocultural significativos. }\end{array}$ \\
\hline & $\begin{array}{l}\text { Coleta, classificação } \text { e } \\
\text { representação de dados } \\
\text { referentes a variáveis } \\
\text { categóricas, por meio de } \\
\text { tabelas e gráficos }\end{array}$ & $\begin{array}{l}\text { (EF03MA28) Realizar pesquisa envolvendo variáveis } \\
\text { categóricas em um universo de até } 50 \text { elementos, organizar os } \\
\text { dados coletados utilizando listas, tabelas simples ou de dupla } \\
\text { entrada e representá-los em gráficos de colunas simples, com e } \\
\text { sem uso de tecnologias digitais. }\end{array}$ \\
\hline
\end{tabular}




\begin{tabular}{|l|l|l|}
\hline Ano & Objetos do Conhecimento & Habilidade \\
\hline $4^{\circ}$ ano & $\begin{array}{l}\text { Leitura, interpretação e e } \\
\text { representação de dados em } \\
\text { tabelas de dupla entrada, } \\
\text { gráficos de colunas simples e e } \\
\text { agrupadas, gráficos de barras } \\
\text { e colunas e gráficos pictóricos }\end{array}$ & $\begin{array}{l}\text { (EF04MA27) Analisar dados apresentados em tabelas simples } \\
\text { ou de dupla entrada e em gráficos de colunas ou pictóricos, com } \\
\text { base em informações das diferentes áreas do conhecimento, e } \\
\text { produzir texto com a síntese de sua análise. }\end{array}$ \\
\cline { 2 - 3 } & $\begin{array}{l}\text { Diferenciação entre variáveis } \\
\text { categóricas e variáveis } \\
\text { numéricas } \\
\text { classificação e representação, } \\
\text { de dados de pesquisa } \\
\text { realizada }\end{array}$ & $\begin{array}{l}\text { (EF04MA28) Realizar pesquisa envolvendo variáveis } \\
\text { categóricas e numéricas e organizar dados coletados por meio } \\
\text { de tabelas e gráficos de colunas simples ou agrupadas, com e } \\
\text { sem uso de tecnologias digitais. }\end{array}$ \\
\hline $\begin{array}{l}\text { 5o ano } \\
\text { Leitura, coleta, classificação } \\
\text { interpretação e representação } \\
\text { de dados em tabelas de dupla } \\
\text { entrada, gráfico de colunas } \\
\text { agrupadas, gráficos pictóricos } \\
\text { e gráfico de linhas }\end{array}$ & $\begin{array}{l}\text { (EF05MA24) Interpretar dados estatísticos apresentados em } \\
\text { textos, tabelas e gráficos (colunas ou linhas), referentes a outras } \\
\text { áreas do conhecimento ou a outros contextos, como saúde e } \\
\text { trânsito, e produzir textos com o objetivo de sintetizar } \\
\text { conclusões. } \\
\text { (EF05MA25) Realizar pesquisa envolvendo variáveis } \\
\text { categóricas e numéricas, organizar dados coletados por meio de } \\
\text { tabelas, gráficos de colunas, pictóricos e de linhas, com e sem } \\
\text { uso de tecnologias digitais, e apresentar texto escrito sobre a } \\
\text { finalidade da pesquisa e a síntese dos resultados. }\end{array}$ \\
\hline
\end{tabular}

Fonte: BNCC (2017).

Nota-se que os objetos de conhecimento e as habilidades apresentam-se em uma escala ascendente em um processo em que deveriam ser ampliados e aprofundados a cada ano escolar.

\section{Delineamento metodológico}

Em uma abordagem de pesquisa qualitativa, os dados permitem compreender as complexidades e os detalhes das informações obtidas. Então, os dados qualitativos caracterizam-se como informações nas quais buscamos não somente medir um tema, mas também descrevê-lo, usando impressões, opiniões e até mesmo pontos de vista. Desse modo, concordamos com Godoy (1995, p. 23) ao afirmar que: "a abordagem qualitativa, enquanto exercício de pesquisa, não se apresenta como uma proposta rigidamente estruturada, ela permite que a imaginação e a criatividade levem os investigadores a propor trabalhos que explorem novos enfoques".

A abordagem qualitativa nos dá liberdade para realizar debates sobre possibilidades de contribuição com a realidade dos sujeitos da pesquisa. Inicialmente, 
houve a preocupação com o contexto atual, pois, desde março do ano de 2020, o mundo se encontra imerso numa pandemia e as aulas presenciais foram suspensas como forma de restringir a aglomeração de pessoas. Adaptou-se o caminho da pesquisa e os instrumentos de constituição das informações, mas foi mantido o propósito de realizar um trabalho em parceria e uma relação bem próxima entre pesquisadores e professoras. De modo geral, o percurso da pesquisa está representado na Figura 1:

Figura 1. Percurso da pesquisa

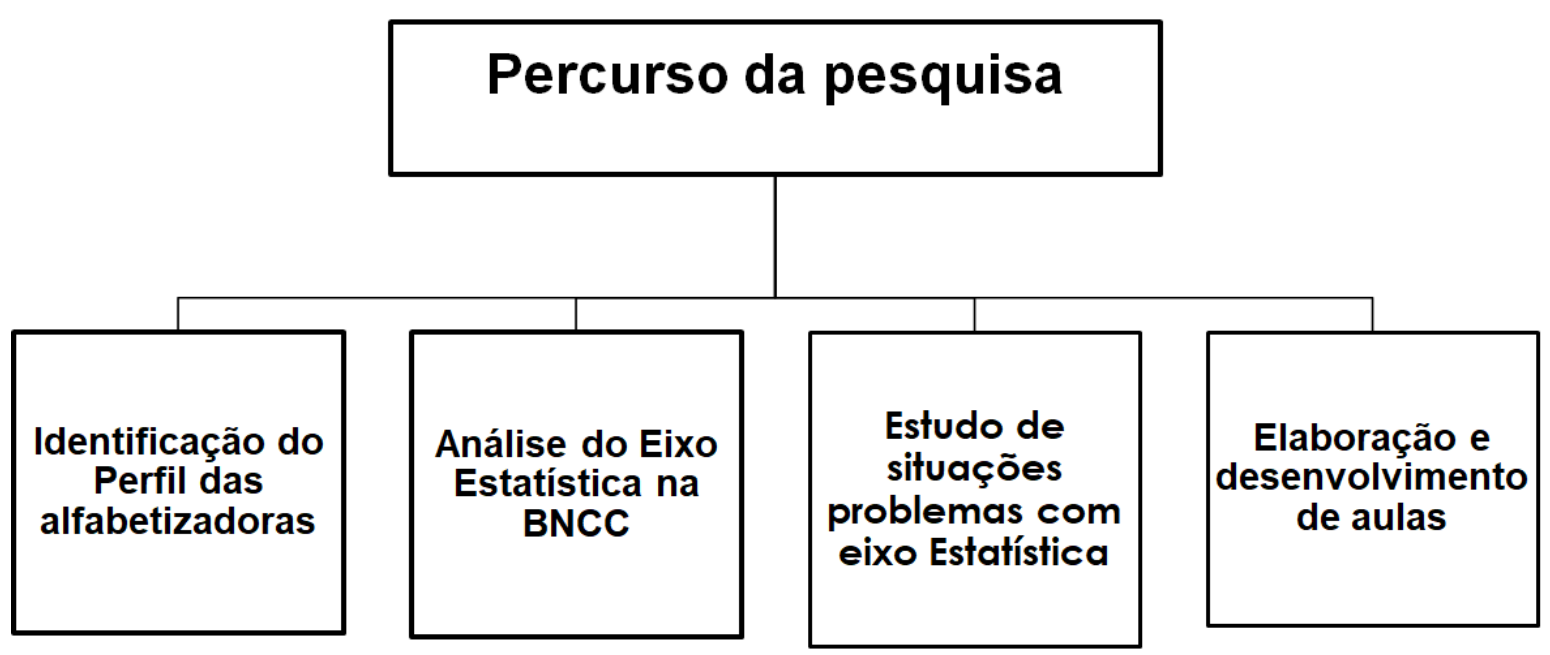

Fonte: Diário do pesquisador.

Realizou-se a identificação e caracterização das escolas, mas a observação participante nas salas de aula foi impossibilitada. Assim, uma alternativa que substituiu a participação in loco do pesquisador foi a gravação da aula em vídeo. Esse vídeo era disponibilizado ao pesquisador para análise. Os principais instrumentos de pesquisa foram: análise do eixo Estatística na BNCC; encontros com as professoras via Google Meet; seleção de situações-problemas no livro didático; elaboração de planos de aulas; desenvolvimento de aulas.

\section{Sujeitos da pesquisa}

Participaram da pesquisa as alfabetizadoras que atuaram, no ano de 2020, no I Período e II Período da Educação Infantil, e nas classes do $1^{\circ}$ ao $5^{\circ}$ ano do Ensino 
Fundamental de duas escolas da rede particular da cidade de Barreiras/BA, pois durante 0 período da pandemia as escolas públicas estavam fechadas.

Foram 14 turmas: 02 turmas de I período, 02 turmas de II período, 02 turmas de $1^{\circ}$ ano, 02 turmas de $2^{\circ}$ ano, 02 turmas de $3^{\circ}$ ano, 02 turmas de $4^{\circ}$ ano, 02 turmas de $5^{\circ}$ ano, mas a professora que ensina matemática nas turmas de $4^{\circ}$ e $5^{\circ}$ ano do Instituto Batista é a mesma; assim, foram 13 professoras e seus estudantes. Ao fazer a leitura desses dados, percebe-se que a maioria das professoras é experiente: 09 professoras têm um tempo de atuação no magistério acima de seis anos; uma professora com 03 anos de atuação; uma professora com 04 anos de atuação e somente uma iniciou a carreira profissional no mês de janeiro daquele ano de 2020.

Em relação ao tempo de atuação como alfabetizadora, viu-se que estava entre poucos meses a 15 anos de atuação. Quanto à afinidade com a Matemática, em resposta à pergunta: Em uma escala de 0 a 10, que nota você daria para sua afinidade com a Matemática? Obtiveram-se os seguintes resultados:

Figura 2. Afinidade com a Matemática

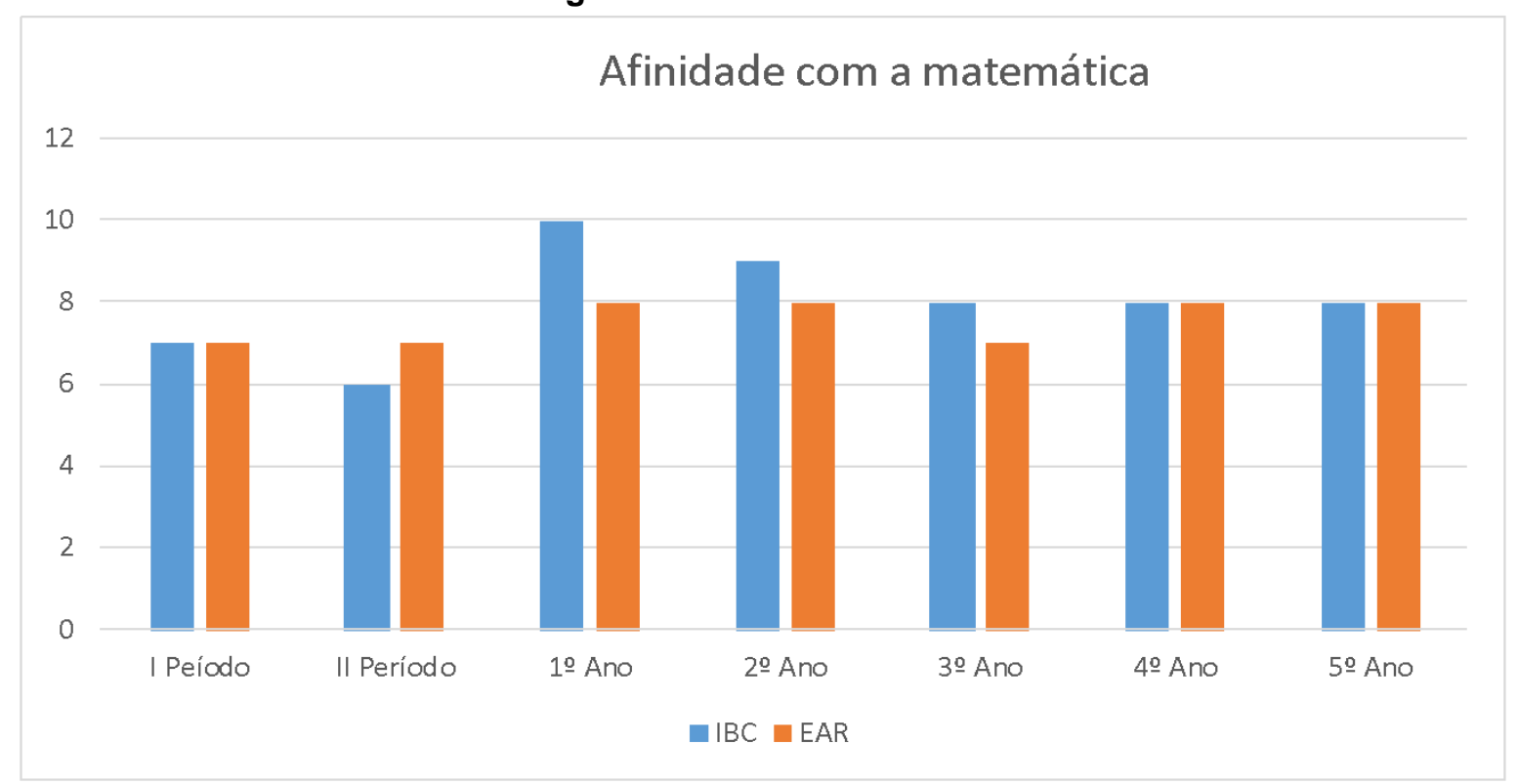

Fonte: Diário do pesquisador.

Percebe-se que as professoras atribuíram uma nota que indica uma boa relação com essa área, mas quando se fez a leitura da resposta subjetiva, observa-se que, mesmo dando notas altas, uma média de aproximadamente 7.8 , elas relataram que não têm um 
domínio satisfatório do conteúdo matemático: "Ficaria com a média 08 , pois não sou muito boa em matemática. Nas séries iniciais é mais fácil para trabalhar, mesmo assim estudo para compreender melhor". É interessante destacar a expressão "não sou muito boa" e, ao mesmo tempo nota 8 , isso pode evidenciar tanto uma relação satisfatória com a matemática, quanto o desejo de ter um conhecimento maior do que aquele que já tem no momento. E a afirmação de que "estudo para compreender melhor" é uma indicação positiva, pois é inerente à profissão professor o aprofundamento nos estudos e o aperfeiçoamento contínuo.

Uma das professoras justificou a dificuldade em matemática: "Pois no curso de Pedagogia não temos um estudo aprofundado da disciplina. O que vemos é somente uma pequena teoria a respeito de como ministrar alguns conteúdos em sala". Essa dificuldade foi apontada em diversos estudos sobre a formação do professor que ensina matemática, pois o curso de formação inicial, em alguns casos, promove uma formação generalista e não específica para o ensino das diferentes áreas de conhecimento que constituem o currículo da Educação Básica.

Destaca-se que as professoras da Educação Infantil são as que indicaram menor afinidade com a matemática. Uma das professoras do II Período da Educação Infantil indicou um valor menor que 7 e observa-se que essa professora apresentou dificuldade em identificar situações-problema referentes à Estatística no livro didático, adotado em sua escola.

Outro questionamento feito na pesquisa foi: Em relação ao Eixo Estatística, como você caracteriza seu trabalho em sala de aula? Os resultados estão representados na Figura 3: 
Figura 3. Caracterização do trabalho com o eixo estatística

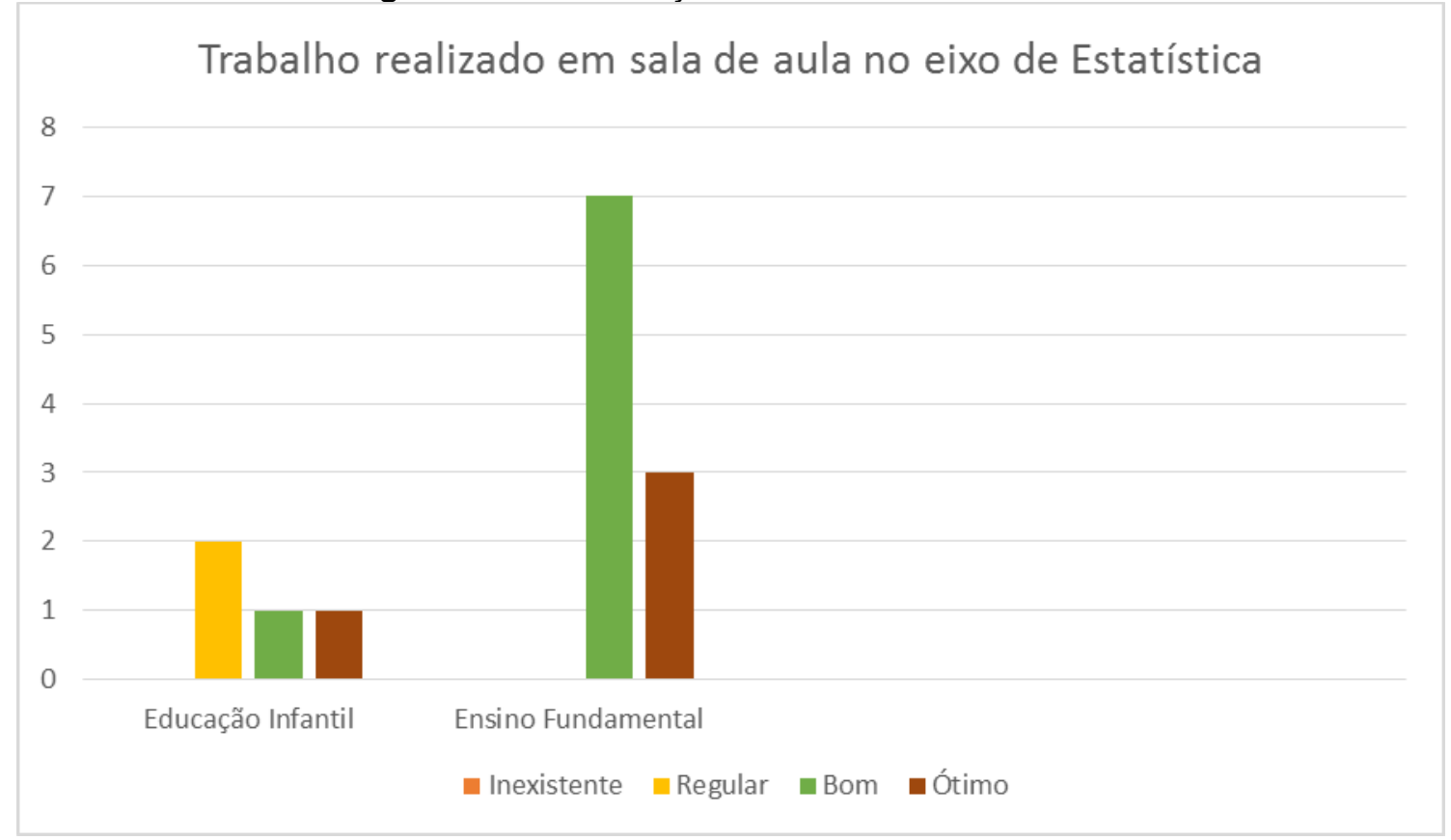

Fonte: Diário de registro do pesquisador.

A indicação de ótimo foi feita pelas professoras do 3ำ 4ำ e 5a ano. Destaca-se que, entre as professoras da Educação Infantil, vê-se uma indicação de um trabalho regular com o eixo Estatística. Esse dado é coerente com a fala da professora do II Período: "Eu estava olhando a entrevista e meu conteúdo... Meu livro não trabalha o eixo de Estatística". Esse trecho revela a dificuldade em identificar as atividades contidas no livro que seriam direcionadas a explorar o Eixo Estatística. Isso evidencia o quanto é necessário realizar um trabalho entre estudantes da pós-graduação em matemática, como o Profmat, e professores atuantes na escola de educação infantil e anos iniciais do Ensino Fundamental. Pesquisas como a de Curi (2004) já indicaram essas lacunas conceituais dos professores que ensinam matemática nesses segmentos, apontando a necessidade da parceria e da participação em grupos de estudo para a superação dessas lacunas que dificultam um desenvolvimento adequado do trabalho com a matemática.

A partir desses questionamentos iniciais, que possibilitaram maior conhecimento do perfil do grupo de professoras, foram propostas a seleção de situações-problemas nos livros didáticos adotados e a elaboração e o desenvolvimento de aulas.

Ressalta-se que apesar do ambiente escolar disponível, nesse ano de 2020, as crianças receberam as atividades para serem realizadas em casa. A dinâmica desse 
trabalho ocorreu da mesma forma nas duas escolas: as professoras planejavam as atividades da semana, imprimiam e colocavam em envelopes individuais para cada estudante da turma; esse envelope era entregue aos pais. Eram atividades referentes a cada dia da semana e, para orientar os estudantes, as professoras encaminharam uma videoaula gravada pela própria professora. Os pais devolviam o envelope com as atividades respondidas e recebiam um novo envelope com as atividades da semana seguinte e com a atividade da semana anterior corrigida pela professora.

O trabalho das professoras em preparar materiais autoinstrucionais para os estudantes, devido à falta da aula presencial, representou uma sobrecarga de trabalho e tornou-se um empecilho para a análise dos materiais em um grupo de Whatsapp, ou via reuniões no Google Meet, pois além de elaborar o plano de sua aula, isso exigiria um olhar atento ao plano elaborado por sua colega de trabalho. Por esse motivo, as discussões ocorreram entre o pesquisador e cada uma das professoras.

\section{Exploração do eixo Estatística na Educação Infantil e Anos Iniciais do Ensino Fundamental}

Os principais resultados da pesquisa de mestrado Profmat/UFOB foram o estudo das competências, habilidades e objetos de conhecimento propostos para o eixo de Estatística na BNCC e a elaboração e o desenvolvimento de aulas com base nesse estudo, o que caracterizou a formação continuada das professoras. Apresentam-se, a seguir, recortes desses resultados.

Houve uma preocupação com as aulas da Educação Infantil, pois como foi relatado pela professora do II Período, "Meu livro não aborda Estatística", o que poderia ser um obstáculo ao desenvolvimento da aula. No entanto, a aula foi realizada de acordo com o plano de aula que o pesquisador e a professoras do I Período e II Período elaboraram juntos.

Na aula do I Período, a professora enviou a atividade para os estudantes, como proposto no período de pandemia; recebeu, analisou as respostas e, posteriormente, enviou aos alunos o vídeo com os resultados da pesquisa, assim como planejado. Nessa aula, observou-se um grande empenho da professora, uma preocupação em confeccionar uma tabela e apresentar para os alunos. Caso fosse um ensino presencial, a elaboração da tabela seria feita de modo coletivo entre alunos e professora. 
Figura 4. Atividade resolvida por um aluno do II Período

Fonte: Diário do pesquisador.

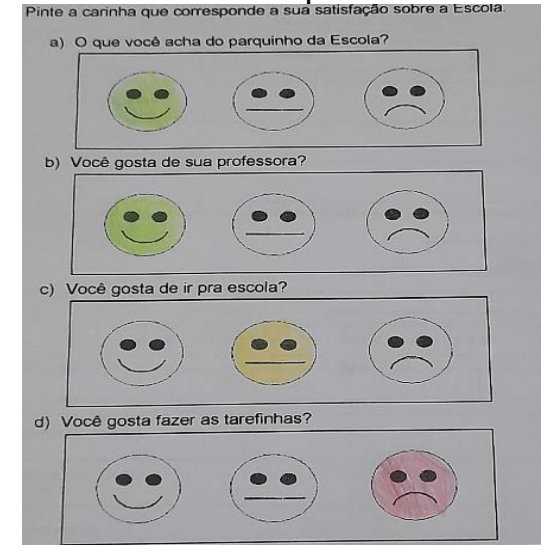

Na aula do II Período, os alunos responderam a uma pesquisa sobre a satisfação de determinados segmentos da escola. As instruções foram enviadas e eles responderam a pesquisa (levantamento de dados) proposta. A professora ainda ministrou mais uma aula, gravada em vídeo, mostrando para os alunos os resultados.

Figura 5. Atividade resolvida por um aluno do II Período

Fonte: Diário do pesquisador.

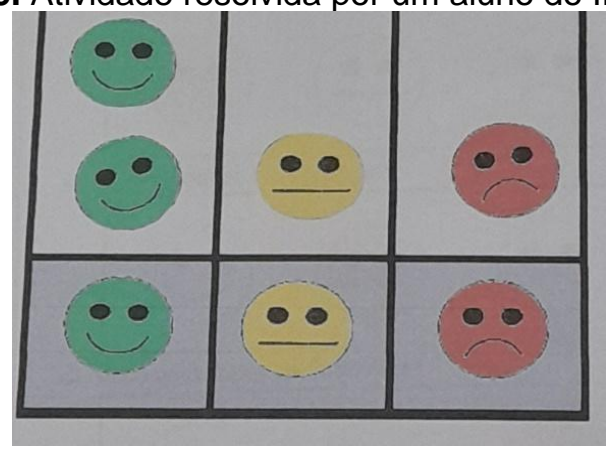

Com essa atividade, os alunos tiveram a oportunidade de iniciar a identificação de um gráfico de colunas, pois essa tabela com as carinhas, classificadas na vertical, lembra um gráfico de colunas, quanto mais alta a coluna, mais escolhida foi a opção.

$\mathrm{Na}$ aula do $1^{\circ}$ ano, foi gravado e postado um vídeo no Youtube e encaminhado para os alunos. Enquanto eles assistiam ao vídeo, iam respondendo a atividade, seguindo as orientações dadas. A professora recebeu as atividades, corrigiu e devolveu para os alunos. O que chamou a atenção, nessa aula, foi a desenvoltura da professora, acolhendo os alunos como se estivessem todos juntos na sala de aula. 


\section{ENSIN@UFMS 2021}

ISSN 2525-7056

Figura 6. Trecho da vídeo-aula

$=$ ondee"

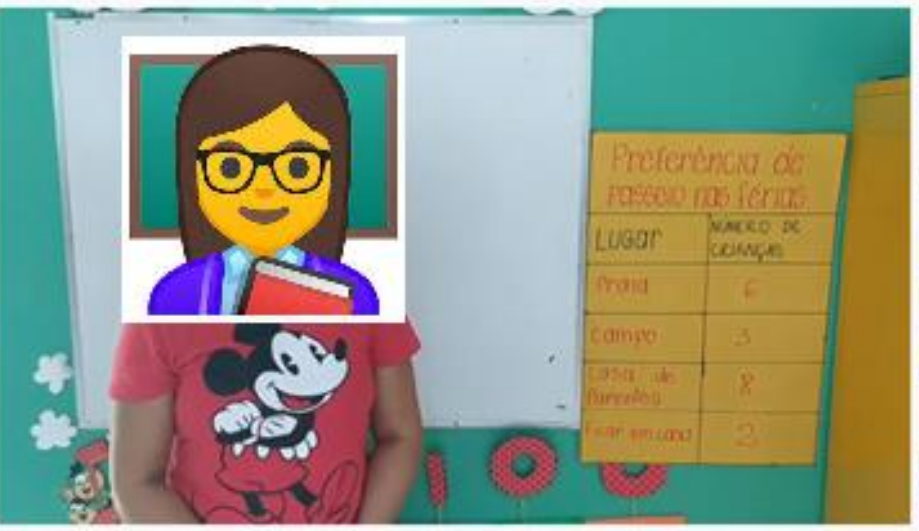

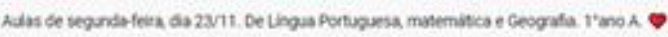

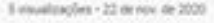

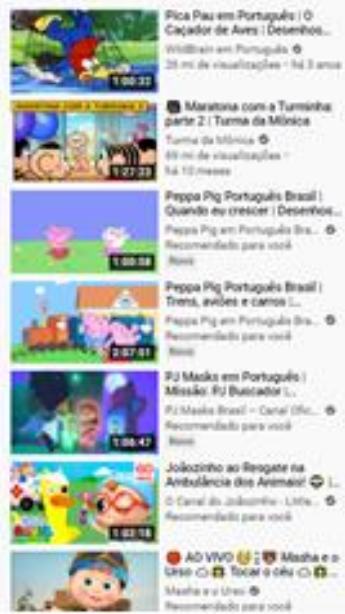

Fonte. Diário de registro do pesquisador.

O planejamento da aula do $4^{\circ}$ ano apresentou uma proposta mais direcionada para oportunizar ao aluno entender como se faz uma pesquisa e mostrar, em atividades práticas, se conseguiu compreender. A professora dividiu a turma em dois grupos, o primeiro pesquisou sobre a cidade onde havia nascido e o segundo sobre o animal de estimação. Muitos alunos tiveram dificuldades no momento de realizar a pesquisa e outros na hora de representar em gráfico ou tabela. A maioria representou em forma de tabela, como mostra a figura 07, poucos colocaram a conclusão dos resultados obtidos na pesquisa.

Figura 7. Atividade resolvida por um aluno do $4^{\circ}$ ano

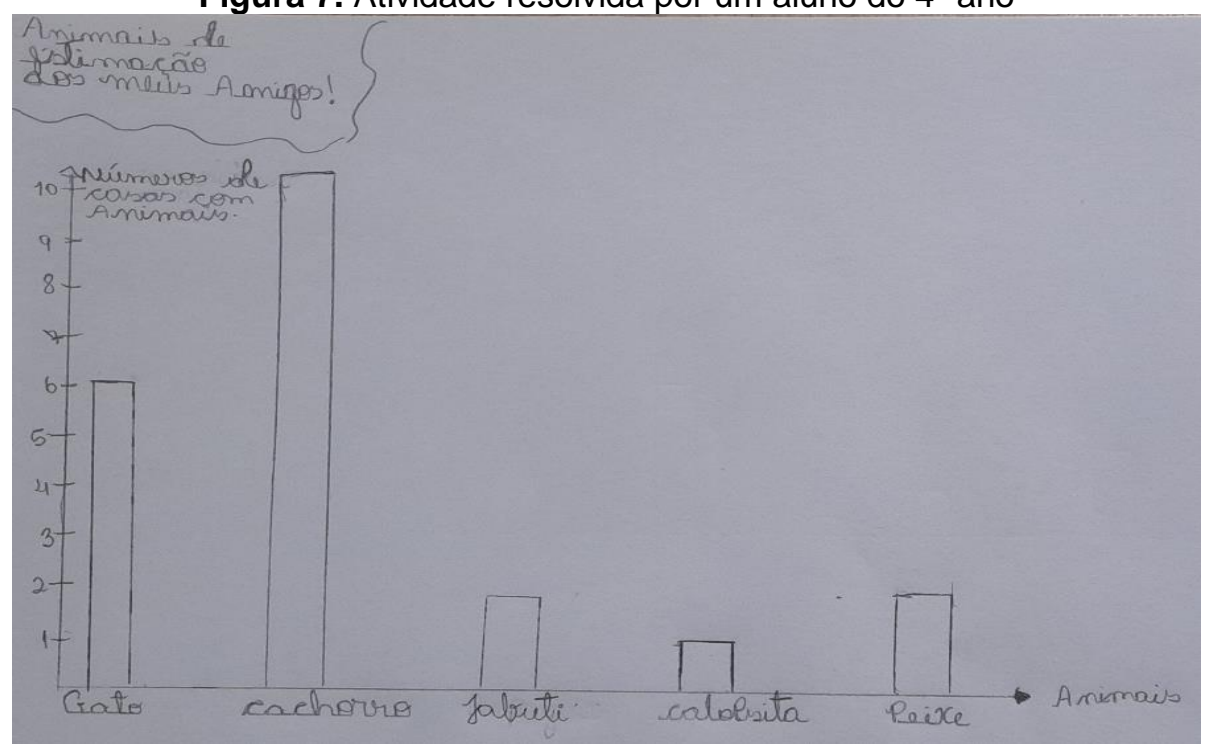

Fonte: Diário do pesquisador. 


\section{ENSIN@UFMS 2021}

ISSN 2525-7056

Destaca-se essa construção do gráfico de um dos alunos, na qual ele colocou corretamente um título para o gráfico, um título para o eixo $\mathrm{x}$ e outro para o eixo $\mathrm{y}$.

$\mathrm{Na}$ aula do $5^{\circ}$ ano, a professora passou um questionário para os alunos, recebeu, analisou e gravou um vídeo mostrando os resultados de cada questionamento. O vídeo foi elaborado de maneira muito interativa, o que demonstrou as novas aprendizagens profissionais da professora, exigidas pelo ensino remoto.

Figura 8. Trecho do vídeo

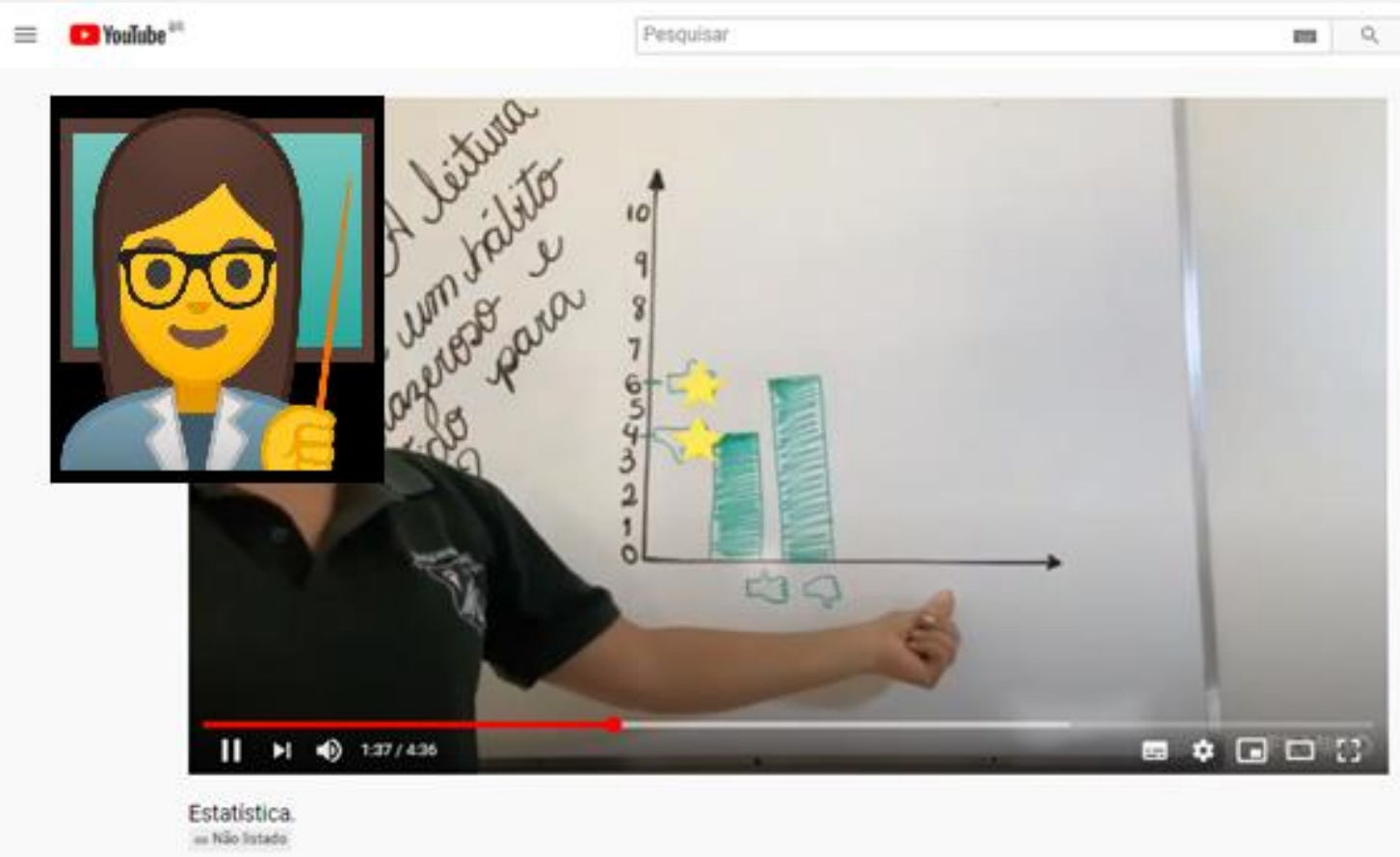

Fonte: Diário do pesquisador.

Nos relatos e conversas com as professoras, de forma geral, foi manifestado um grande aprendizado, pois antes não compreendiam que a alfabetização no eixo de Estatística era um processo contínuo da Educação Infantil ao Ensino Fundamental. Relataram também que, a partir de 2021, o eixo de Estatística será explorado de forma diferente, enfatizando sua importância e mostrando sempre para os alunos sua presença em outros componentes curriculares. A seguir, apresentamos alguns recortes das falas das professoras, quando perguntadas sobre a contribuição do trabalho para sua formação profissional. Professora A pontuou:

Como profissional, posso afirmar que seu excelente trabalho não só contribuiu para a formação profissional, como também abriu leques de possibilidades, para que nós profissionais possamos buscar sempre inovar nas aulas de matemática, seja 
através da estatística ou de outros temas abordados. E seremos capazes de estimular no educando o desenvolvimento das capacidades de pensamento lógico e da autonomia.

Professora B:

Afirma o que já fizemos na nossa metodologia, o que você abordou na sua pesquisa confirma o que fazemos e que podemos aperfeiçoar cada vez mais.

Professora C:

Principalmente quando elaboramos as aulas juntos, cada um colocando sua metodologia, manifestando suas experiências e trocando informações. Nossas aulas a partir do dia da pesquisa, está sendo planejada de forma diferente.

Professora D:

Gostei muito da metodologia, trabalhamos de forma coletiva e vimos que a educação é um processo que devemos estar sempre nos atualizando e buscando novas formas de ensinar.

Em relação aos alunos, foi surpreendente o seu envolvimento, levaram as aulas de forma divertida e descontraída. Com essa descontração, conseguimos ter a atenção do aluno, fazendo com que eles colaborassem com a pesquisa e tivessem um grande aproveitamento no aprendizado. Toda essa interação por parte dos alunos pode ser devido à voz que eles ganharam, respondendo as pesquisas, fazendo pesquisas, manifestando o seu grau de satisfação. Isso está de acordo com as indicações de Gitirana (2014) sobre proporcionar o fazer pesquisa desde a Educação Infantil.

\section{Considerações Finais}

A análise da BNCC para o eixo de estatística aponta que as crianças da Educação Infantil devem desenvolver habilidades que lhes proporcionem registrar com números a quantidade de crianças (meninas e meninos, presentes e ausentes), a quantidade de objetos da mesma natureza (bonecas, bolas, livros etc.) e construir gráficos básicos. Essas habilidades foram exploradas com êxito nas aulas em parceria com as professoras colaboradoras.

Diante disso, observou-se que se trata de uma orientação capaz de tornar a aula mais interessante, estreitando os laços entre professor e aluno durante a realização de pesquisa e busca por esses dados, que estão integrados em situações familiares às crianças.

$\mathrm{Na}$ proposição de desenvolver uma pesquisa em parceria, destaca-se a troca de experiências, sugestões e, ao mesmo tempo, a reflexão sobre a prática docente, mesmo 
sem a realização de encontros presenciais. Além disso, este trabalho contribuiu para o aperfeiçoamento da prática docente, bem como para o advento de novas práticas, com o uso de métodos diversificados e, consequentemente, abre um leque de oportunidades para a melhoria da qualidade da educação oferecida em todos os níveis. Este estudo, inclusive, tem impacto na associação da Universidade, a nível de pós-graduação, via Profmat, com o Ensino Básico.

Os objetivos foram alcançados, as ações da pesquisa conduziram as professoras a repensarem suas práticas, elaborando suas próprias tarefas, ou adaptando tarefas à realidade dos seus alunos. Além disso, oportunizou ao mestrando a ampliação da sua visão sobre a atividade do professor que atua nos Anos Iniciais e o aperfeiçoamento de seu trabalho como coordenador pedagógico da área de Matemática. Como continuidade da pesquisa, pretende-se ampliar o referencial teórico, implementar outras práticas de alfabetização e realizar novas parcerias em aulas presenciais no período pós-pandemia, expandindo para a rede pública de ensino.

A releitura da investigação sensibilizou os professores formadores do Profmat/UFOB, com formação específica em matemática, para estabelecer parcerias com os professores da educação básica. Espera-se que esses resultados possam contribuir com a alfabetização matemática no eixo de Estatística, além de evidenciar sua grande importância na continuidade da vida escolar e sua implementação no cotidiano das pessoas.

\section{Referências}

BRASIL. Lei n. 9.394/96. Lei de Diretrizes e Bases da Educação Nacional. Brasília, 1996. Disponível em: http://www.planalto.gov.br/ccivil_03/Leis/L9394.htm. Acesso em: Ago. 2021.

BRASIL, Ministério da Educação. Base Nacional Curricular Comum - BNCC. Brasília, 2018.

CURI, E. Formação de Professores Polivalentes: uma análise dos conhecimentos para ensinar Matemática e das crenças e atitudes que interferem na constituição desses conhecimentos. Tese de Doutorado. PUC/SP. São Paulo. 2004.

CURI, E. A formação matemática de professores dos anos iniciais do ensino fundamental face às novas demandas brasileiras. Revista Iberoamericana De Educación, v. 37, n. 5, p. 1-10, 2006. Disponível em: https://doi.org/10.35362/rie3752687 Acesso em: jul. 2021. 
GATTI, Bernadete. A formação de professores no Brasil: características e problemas. Educação e Sociedade, Campinas, v. 31, n. 113, p. 1355-1379, out.- dez. 2010. Disponível em: http://www.cedes.unicamp.br. Acesso em: jul. 2021.

GITIRANA, V. A pesquisa como eixo estruturador da educação estatística. In: BRASIL. Pacto Nacional pela Alfabetização na Idade Certa: Educação Estatística. Ministério da Educação, Secretaria de Educação Básica, Diretoria de Apoio à Gestão Educacional. Brasília: MEC, SEB, 2014.

GODOY, A. Introdução à pesquisa qualitativa e suas possibilidades. 1995. Disponível em: https://www.scielo.br/pdf/rae/v35n2/a08v35n2.pdf. Acesso em: abril 2021.

NASCIMENTO, A. M. P. A construção coletiva de uma práxis emancipatória em alfabetização matemática. 2016. Tese (Doutorado em Educação)- Programa de PósGraduação em Educação, Universidade de Brasília - UnB, 2016.

\section{SANTOS, E. O. dos S. A formação continuada na rede municipal de ensino do}

Recife: concepções e práticas de uma política em construção. 2010. Tese (Doutorado)Centro de Educação. Universidade Federal de Pernambuco, 2010.

\section{NOTAS}

\section{IDENTIFICAÇÃO DE AUTORIA}

Ana Maria Porto Nascimento. Doutora em Educação pela Universidade de Brasília. Professora e Orientadora do Programa de Mestrado Profissional em Matemática em Rede Nacional (Profmat) da Universidade Federal do Oeste da Bahia (UFOB), BA, Brasil.

E-mail: ana.nascimento@ufob.edu.br

(iD) https://orcid.org/0000-0003-2048-5554

Arthur do Amaral Rocha. Mestre em Matemática pelo Programa de Mestrado Profissional em Matemática em Rede Nacional (Profmat) da Universidade Federal do Oeste da Bahia (UFOB), BA, Brasil.

E-mail: arthur_rocha99@hotmail.com

(1) https://orcid.org/000-0002-1406-8861

Fabiana Alves dos Santos. Doutora em Matemática pela Universidade Federal do Ceará (UFC). Professora Adjunta da Universidade Federal do Oeste da Bahia (UFOB), BA, Brasil.

E-mail: fabiana.santos@ufob.edu.br

(iD) https://orcid.org/0000-0002-5271-9231

Priscila Santos Ramos. Mestre em Matemática pelo Instituto de Matemática da Universidade Federal de Alagoas (UFAL), Doutoranda em Matemática pela Universidade Estadual de Campinas (UNICAMP). Professora adjunta da Universidade Federal do Oeste da Bahia (UFOB), BA, Brasil.

E-mail: priscilasr@ufob.edu.br

(iD) https://orcid.org/0000-0003-3394-764X

\section{AGRADECIMENTOS}

Agradecemos ao Profmat e às professoras colaboradas da pesquisa.

\section{FINANCIAMENTO}

Não se aplica. 


\section{CONSENTIMENTO DE USO DE IMAGEM}

Não se aplica.

\section{APROVAÇÃO DE COMITÊ DE ÉTICA EM PESQUISA}

Não se aplica.

\section{LICENÇA DE USO}

Autores mantêm os direitos autorais e concedem à revista ENSIN@ UFMS - ISSN 2525-7056 o direito de primeira publicação, com o trabalho simultaneamente licenciado sob a Licença Creative Commons Attribution (CC BY-NC-SA 4.0), que permite compartilhar e adaptar o trabalho, para fins não comerciais, reconhecendo a autoria do texto e publicação inicial neste periódico, desde que adotem a mesma licença, compartilhar igual.

\section{EDITORES}

Patricia Helena Mirandola Garcia, Eugenia Brunilda Opazo Uribe, Gerson dos Santos Farias.

\section{HISTÓRICO}

Recebido em: 13/09/2021 - Aprovado em: 03/11/2021 - Publicado em: 15/12/2021.

\section{COMO CITAR}

NASCIMENTO, A. M. P; ROCHA, A. A; SANTOS, F. A; RAMOS, P. S. Formação Continuada de Professores: Parceria entre Profmat, Educação Infantil e Anos Iniciais do Ensino Fundamental. Revista ENSIN@ UFMS, Três Lagoas, v. 2, número especial, p. 229-249. 2021. 